\title{
La verdad duele (2015). El cine y las conmociones cerebrales en los deportes de contacto
}

\author{
Miguel ABAD VILA \\ Hospital Comarcal de Verín. Xerencia de Xestión Integrada de Ourense, Verín e O Barco de Valdeorras (España). \\ Autor para correspondencia: Miguel Abad Vila. Correo electrónico: mabadvila@gmail.com \\ Recibido el 24 de agosto de 2018; aceptado el 13 de octubre de 2018.
}

Cómo citar este artículo: Abad Vila M. La verdad duele (2015). El cine y las conmociones cerebrales en los deportes de contacto. Rev Med Cine [Internet] $2019 ; 15(3):$ 167-184. DOI: http://dx.doi.org/10.14201/rmc2019153167184

\section{Resumen}

La práctica de los deportes de contacto (fútbol americano, rugby, boxeo, artes marciales mixtas) está relacionada con un incremento en el riesgo de padecer conmociones o contusiones cerebrales, provocadas generalmente por traumatismos craneoencefálicos. Al respecto, La verdad duele / Concussion (2015) de Peter Landesman nos muestra el conflicto originado por las investigaciones del Doctor Bennet Omalu y la poderosa National Football League (NFL), la institución representativa del fútbol americano en los Estados Unidos de Norteamérica.

Palabras clave: conmoción cerebral; traumatismo craneoencefálico; deportes de contacto.

\section{Concussion (2015). Cinema and concussions in contact sports}

\begin{abstract}
Summary
The practice of contact sports (American football, rugby, boxing, mixed martial arts) is associated with an increase in the risk of suffering concussions or brain contusions by athletes, usually caused by traumatic brain injuries. In this regard, Concussion (2015) by Peter Landesman shows us the conflict originated by the research of Doctor Bennet Omalu and the powerful National Football League (NFL), the representative institution of American football in the United States of America.
\end{abstract}

Keywords: concussion; traumatic brain injuries; contact sports. 


\section{Ficha técnica}

Título: La verdad duele.

Título Original: Concussion.

Otros títulos: La verdad oculta (América de habla hispana).

País: Estados Unidos.

Año: 2015.

Director: Peter Landesman.

Música: James Newton Howard.

Fotografía: Salvatore Totino.

Montaje: William Goldenberg.

Guión: Peter Landesman, basado en el artículo Game Brain de Jeanne Marie Laskas, publicado en 2009 en la revista Gentelmen's Quarterly.

Intérpretes: Will Smith (Doctor Bennet Omalu), Alec Baldwin (Doctor Julian Bailes), Albert Brooks (Doctor Cyrill Wecht), Gugu Mbatha-Raw (Prema Mutiso), David Morse (Mike Webster), Arliss Howard (Doctor Joseph Marron), Mike O`Malley (Daniel Sullivan), Eddie Marsan (Doctor Steve DeKosky), Hill Harper (Christopher Jones), Adewale Akinnuoye-Agbaje (Dave Duerson), Stephen Moyer (Doctor Ron Hamilton), Richard T. Jones (Andre Waters), Paul Reiser (Doctor Elliot Pellman), Luke Wilson (Roger Goodell), Sara Lindsay (Gracie).

Color: color

Duración: 123 minutos.

Género: biografía, drama, deporte.

Productoras: The Cantillon Company, LStar Capital, Scott Free Productions, The Shuman Company, Village Roadshow Pictures.

Sinopsis: "el Doctor Bennet Omalu (Will Smith) trabaja como patólogo forense en Pittsburg. A raíz de sus investigaciones descubre que varios jugadores profesionales de fútbol americano padecen las secuelas del conocido como síndrome post-conmoción cerebral. Además de los trastornos neurológicos, algunas estrellas de la NFL como Dave Duerson y Junior Seau llegaron a desarrollar conductas suicidas" (FilmAffinity).

Premios: Globos de Oro - nominada en 2016 al Globo de Oro al Mejor Actor Dramático (Will Smith).

\section{Enlaces:}

http://www.imdb.com/title/tt3322364/?ref =ttmd md nm http://www.filmaffinity.com/es/film715071.html

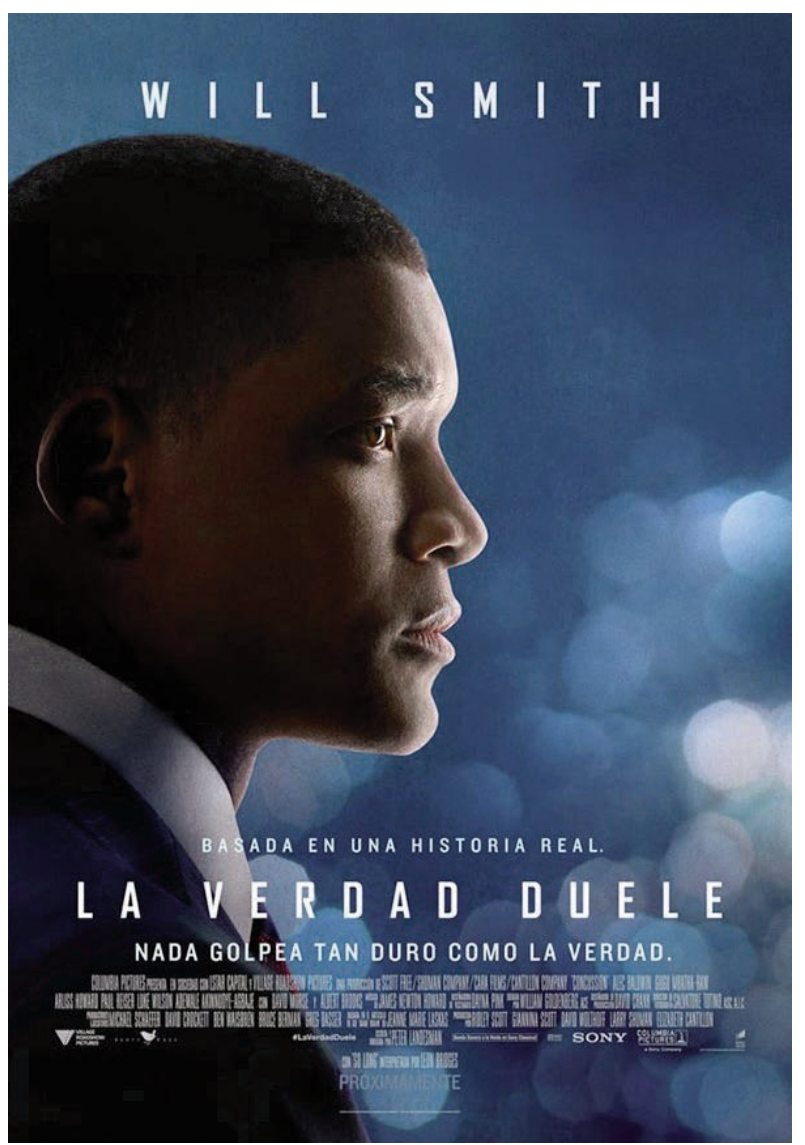

“Cuando haya pitado 3 veces, buscáis a un compañero, cualquier compañero, y chocad contra él. Sed efectivos, ised violentos!"

"La forma de neutralizar a ese jugador es agarrándolo por el cuello y apretando. Aprieta hasta que le corra la mierda por las piernas. ¿Te has enterado?

Arengas semejantes constituyen una parte habitual de la jerga escuchada en los entrenamientos profesionales del fútbol americano, o por lo menos así nos lo cuentan en La verdad duele / Concussion (2015) de Peter Landesman.

En el año 2012, una investigación patrocinada por la propia National Football League (NFL) dejó al descubierto una trama de recompensas que implicaba a los jugadores defensivos de los New Orleans Saints. Entre 2009 y 2011, por cada lesión provocada a un rival, recibieron generosas gratificaciones ${ }^{1}$. De tan canallesco proceder, entre 22 y 27 jugadores de los Saints se habrían beneficiado económicamente. Esto podría haber sido una excepción, si no fuera porque varios de los implicados confirmaron que tales remuneraciones habían existido desde siempre en esta competición. 
En aquellos meses, sacar a un adversario del campo se pagaba a 1000 dólares. Dejarlo fuera de combate para el resto del partido suponía 1500 dólares. Estas cantidades podrían doblarse e incluso triplicarse durante las eliminatorias de play off. Mediante estas marrullerías Kurt Warner (180 cm y 99 kilos), el quarterback de los Arizona Cardinals, fue "jubilado" en el 2009 durante el transcurso del que fuera su último partido como profesional.

Así de cruel fue en realidad. En la ficción cinematográfica, la retirada prematura de la estrella del equipo y su sustitución por un jugador suplente constituye la línea argumental de Juego de Campeones / Varsity Blues (1999) de Brian Robbins. Jonathan Mox Moxon (James Van Der Beek) se ve obligado a reemplazar a Lance Harbor (interpretado por el malogrado Paul Walker), el descalabrado astro de los West Caan Coyotes, a las órdenes del inflexible entrenador Bud Kilmer (Jon Voight). En contraposición Harold Jones (Ed Harris), aquel otro adiestrador de Me llaman Radio / Radio (2003) de Mike Rich, se esforzó en la integración del joven discapacitado de color James Robert Radio Kennedy (Cuba Gooding Jr) en el equipo de fútbol americano del Instituto T.L. Hanna High School de Carolina del Sur, en un alegato cinematográfico contra el racismo inspirado en el artículo Someone to Lean On de Gary Smith², publicado en la revista Sports Illustrated el 16 de diciembre de 1996.

La participación de jugadores de color en las ligas universitarias (y posteriormente en el fútbol profesional) constituye el eje central de El expreso de Elmira / The Express (2008) de Gary Fleder. Basada en hechos reales, el joven running back Ernie Davis (Rob Brown) se pone a las órdenes del entrenador Ben Schwartzwalder (Dennis Quaid) para ganar dos títulos consecutivos con la Universidad de Syracuse y el prestigioso Trofeo Heisman, como el primer mejor jugador de color de la NCAAF (la liga universitaria de fútbol americano).

El cine ha sido mucho más indulgente con uno de los deportes estadounidenses más populares (junto al beisbol y el baloncesto). Su práctica ha sido harto sugestiva para desvelar historias ejemplares de esfuerzo y superación, como por ejemplo Rudy, reto a la gloria / Rudy (1993) de David Anspaugh, en la que el joven Daniel Rudy Ruttiger (Sean Astin) anhelaba convertirse en jugador de la Universidad de Notre Dame (Indiana), a pesar de no disponer de la necesaria beca deportiva. El guión fue obra de Angelo Pizzo, el mismo creador de Hoosiers, más que ídolos / Hoosiers (1986) de David Asparaugh, en esta ocasión aclamando el mítico triunfo del modesto equipo de baloncesto del Instituto Milán de Indiana en 1954, con Gene Hackman y Dennis Hooper al frente de su elenco artístico.

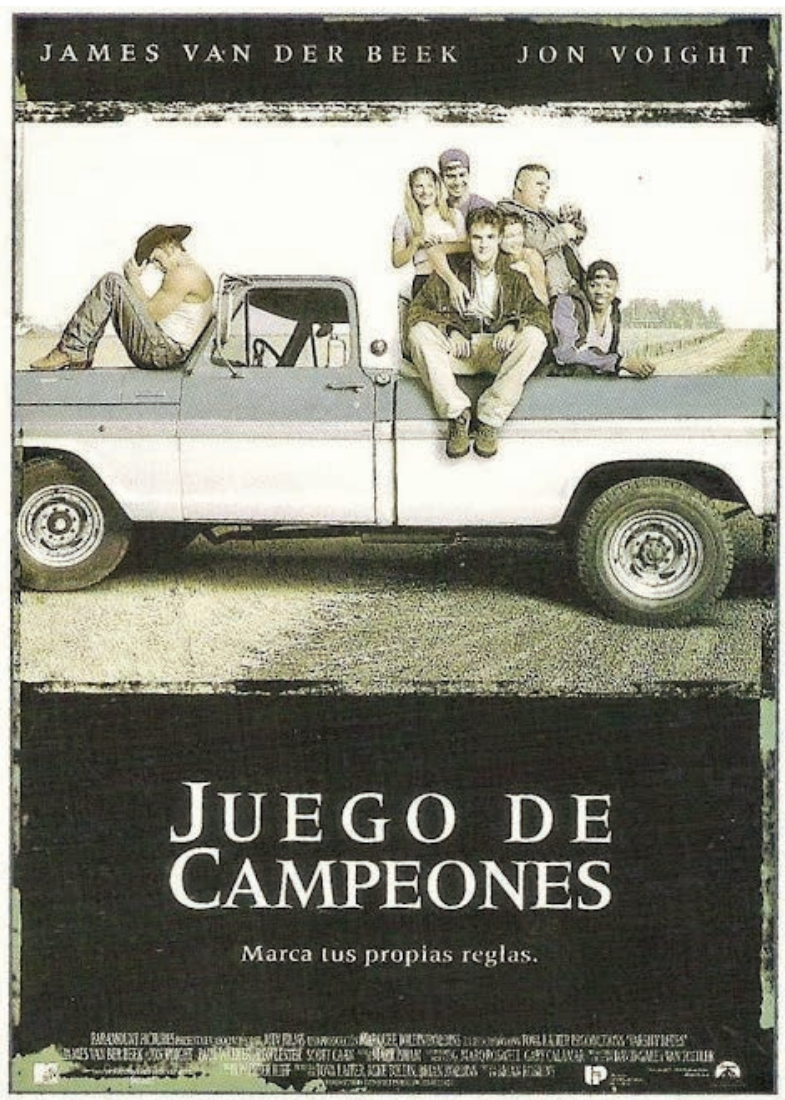

Un par de décadas más tarde, el actor Sean Astin protagonizó una nueva película relacionada con el fútbol americano, esta vez encarnando al entrenador Hank Erwin. Se trata de Woodlaw (2015) de los hermanos Andrew y John Erwin, un drama deportivo de temática religiosa antagónico al segregacionismo y la intolerancia. En el mismo sentido, Invencible / Invincible (2006) de Ericson Core se inspiró en una historia real, la protagonizada por el camarero Vince Papale (Mark Walhberg) que, en 1976, a los 30 años de edad, debutó como receptor en el equipo profesional de los Philadelphia Eagles.

En una vertiente más amable se sitúa la comedia Equipo a la fuerza / The Replacements (2000) de Howard Deutch, donde un grupo de jugadores aficionados es requerido para completar la temporada de los Washington Centinels. De esta manera, Shane Falco (Keanu Rives) culmina un sueño personal a las órdenes del entrenador Jimmy McGinty (Gene Hackman).

Con anterioridad, El Rompehuesos / The Longest Yard (1974) de Robert Aldrich, empleó la vena cómica para mostrarnos la historia de Paul Wrecking Crewe (Burt Reynolds), un jugador profesional de futbol americano 
condenado a prisión y encargado de formar y entrenar a un equipo de reclusos para enfrentarse a sus guardianes. En la realidad, el fornido actor no llegó a debutar en la NFL a causa de una desafortunada serie de lesiones en las rodillas. Ray Nitschke, en su día estrella de los Green Bay Packers, participó en el reparto de este film. En 1962 formó parte de una de las mejores defensas de la historia de la NFL. El clan de los rompehuesos / The Longest Yard (2005) de Peter Segal es un remake en el que Adam Sandler encarna a Paul Crewe, contando con una notable presencia de jugadores transformados en actores ocasionales: Michael Irvin (campeón con los Dallas Cowboys), Bill Romanowski (San Francisco 49ers, Denver Broncos, Oakland Riders) y Terry Crews (Los Ángeles Rams, San Diego Chargers, Washington Redskins y Philadelphia Eagles). El papel del entrenador Nate Scarborough fue interpretado por el propio Burt Reynolds.

En El aguador / The Waterboy (1999) de Frank Coraci, Adam Sandler encarnó a Robert Boby Boucher Jr, un apocado auxiliar de un equipo de futbol americano que le toca debutar a los 33 años como jugador defensivo en el estadio. Por su intervención en esta floja comedia de corte estudiantil, Sandler fue nominado al Premio Razzle como peor actor.

Concussion es el título original de La verdad duele (2015) de Peter Landesman, el término técnico traducido como conmoción o contusión cerebral, generalmente provocada por un traumatismo craneoencefálico y que cursa con una pérdida temporal de las funciones cerebrales.

Cuando el quebranto de la conciencia, la confusión y la desorientación duren menos de 30 minutos, la intensidad del episodio se califica como leve. Su sintomatología resulta variable, con manifestaciones físicas, cognitivas y emocionales que incluso pueden llegar a pasar desapercibidas: pérdida de conciencia, amnesia, cefalea, visión borrosa, diplopía, inestabilidad emocional (incluyendo irritabilidad, frustración y agresividad), pérdida de concentración, disminución del tiempo de reacción y trastornos del sueño. Y aunque las pruebas diagnósticas de imagen (TAC, RNM) pueden ser normales, los efectos individuales y familiares de esta patología pueden resultar devastadores.

Desde el punto de vista médico y cinematográfico, ésta no es la primera vez que La verdad duele es comentada en esta revista ${ }^{3}$. Basada en hechos reales, el guión del propio director fue inspirado por el artículo periodístico Game Brain (2009) de la escritora y profesora Jeanne Marie Laskas ${ }^{4}$, relacionado con los descubrimientos del

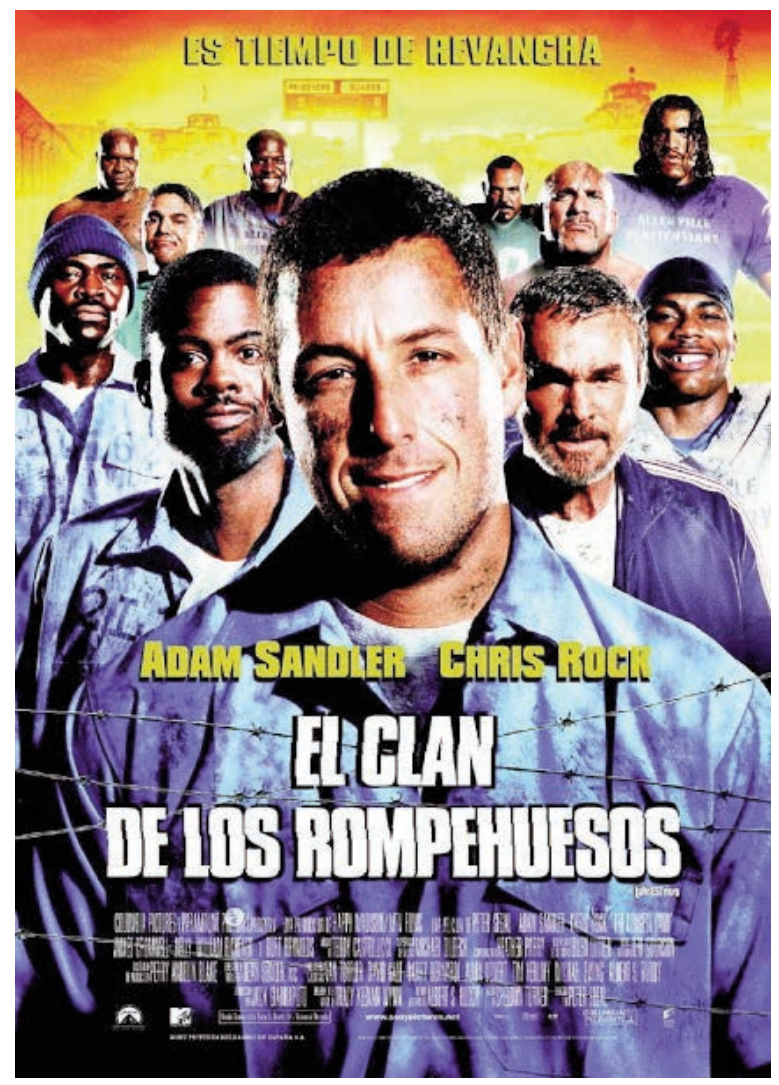

patólogo forense de origen nigeriano, el Doctor Bennet Omalu (Will Smith) respecto a la encefalopatía crónica traumática en los jugadores profesionales de fútbol americano. Sus revelaciones llevaron a este tenaz galeno a enfrentarse directamente contra la todopoderosa NFL, que aproximadamente recibe cada año 3000 millones de dólares por sus derechos televisivos.

Con anterioridad, este tipo específico de patología encefálica neurodegenerativa se conocía como demencia pugilítistica o punch drunk syndrome, causada por la repetición de traumatismos cerebrales, de intensidad variable y asintomáticos en la mayoría de las ocasiones. Fue descrita por primera vez en los boxeadores. Además de en el fútbol americano, recientemente ha sido también relacionada con otros deportes de contacto, como por ejemplo el hockey sobre hielo, las artes marciales mixtas y el rugby.

En 1928, el patólogo forense estadounidense Harrison S. Martland (1883 - 1954) explicaba por primera vez las lesiones y los síntomas padecidos por diversos boxeadores, dependiendo de la duración de sus carreras deportivas y de la cantidad e intensidad de los golpes recibidos de manera reiterada en sus cabezas ${ }^{5}$. En la 
década de los años 70 del pasado siglo XX, después de valorar a un número considerable de púgiles afectados por este tipo de trastorno, los expertos concluyeron que se trataba de una patología específica y distinguible del resto de las enfermedades neurodegenerativas.

Las conmociones cerebrales están causadas por repentinas fuerzas de aceleración y deceleración provocadas por un golpe o un placaje (independientemente de la parte del cuerpo receptora del impacto), así como por la rotación forzada de la cabeza.

\section{Lesiones encefálicas en los boxeadores}

El 12 de junio de 1982, el articulista David Noonan publicada Boxing and the Brain en el Magazine del New York Times ${ }^{6}$, una seria advertencia sobre el número de decesos ocurridos sobre los cuadriláteros provocados por traumatismos cerebrales. Cualquier intento por reducir la morbimortalidad pugilística pasaba indefectiblemente por el conocimiento científico de los efectos del boxeo sobre el encéfalo de los púgiles.

Los efectos a corto plazo podrían ir desde una conmoción hasta una hemorragia cerebral, e incluso la muerte. A largo plazo, las consecuencias constituían la entidad particularmente conocida como demencia pugilística, encefalopatía crónica de los boxeadores o síndrome de los puñetazos.

Al comenzar un combate, diversas partes del encéfalo del boxeador comienzan a trabajar coordinadamente. La formación reticular, en el núcleo del tronco encefálico, interactúa con otras estructuras que controlan sus movimientos, el funcionamiento del aparato cardiovascular y que además recogen la información sensorial procedente del sistema nervioso central.

Diferentes áreas de la corteza cerebral procesan estímulos visuales y auditivos. La sangre oxigena músculos y encéfalo. La capacidad de razonar del púgil se encuentra plenamente operativa. De repente, comienza a recibir golpes en la cabeza, puesto que su intención (y la de su rival, por supuesto) es tratar de finalizar el combate por la vía rápida, atacando estratégicamente y sin pausa la parte más vulnerable de su anatomía.

Mediante técnicas de TAC cerebral y según los informes de sus autopsias, se establecieron tres características anatómicas descriptivas de la demencia pugilística:

1. Atrofia cortical: durante años, los movimientos persistentes de rebote cerebral contra el cráneo provocan la erosión de las neuronas corticales. La corteza cerebral se desgasta y adelgaza debido a la pérdida progresiva del tejido neuronal.

2. Dilatación de los ventrículos, el lugar donde se produce el líquido cefalorraquídeo.

3. Cavum septum pellucidum: orificio en la membrana que separa dos de los ventrículos como resultado de las fuerzas de concusión en el centro del cerebro. Este hallazgo anatómico, aunque menos aparente, puede acarrear graves consecuencias clínicas, como por ejemplo déficit de la memoria, marcha inestable (al encontrase también implicados el cerebelo y el propio tronco encefálico) y temblor. El temblor de los boxeadores puede deberse a afecciones del tálamo y la sustancia negra, estructuras críticas relacionadas con la enfermedad de Parkinson.

Entonces, ¿cuál fue la relación entre los descubrimientos del Doctor Omalu en los cerebros de los jugadores profesionales de fútbol americano con aquellos otros detectados anteriormente en los boxeadores?

En una escena de La verdad duele (2015) de Peter Landesman, el protagonista (Will Smith) consulta diversos tratados y artículos de investigación. Uno de ellos es Medical aspects of boxing, particulary from a neurological standpoint ${ }^{7}$, publicado en 1957 por el Doctor MacDonald Critchley, prestigioso neurólogo del King's College Hospital de Londres (Gran Bretaña). En el año 1949, este especialista había estudiado 21 casos de encefalopatía crónica pugilística. El tiempo promedio desde el inicio de la actividad competitiva hasta la aparición del trastorno neurodegenerativo fue de 16 años (oscilando entre los 6 y los 40 años). Las evidencias clínicas detectadas apuntaban al efecto acumulativo de pequeñas lesiones cerebrales a lo largo del tiempo, que involucraban a las principales áreas cerebrales, con variaciones personales en cada caso.

La mayor parte de la literatura médica al respecto ha recopilado datos procedentes de boxeadores amateur, siendo más bien escasos los realizados con profesionales. De su estudio y análisis sabemos que entre el 25 y el $95 \%$ de las lesiones se producen en la cabeza (contusiones y laceraciones) y la mayoría de intensidad leve.

Los medios de protección no resultan completamente seguros a la hora de evitar lesiones y traumatismos; siempre y cuando no se tomen las medidas de seguridad oportunas, las lesiones encefálicas podrán resultar irreversibles. Tras el trágico fallecimiento sobre la lona del boxeador surcoreano Duk-Koo Kim el 18 de noviembre de 1982, durante el combate por el Campeonato Mundial de los pesos ligeros contra Ray 
Boom Boom Mancini en Las Vegas, el casco protector fue incorporado como equipamiento habitual para los boxeadores en las Olimpiadas de Los Ángeles 1984. Unos 30 años más tarde, los boxeadores olímpicos y púgiles amateur se subieron al cuadrilátero en las Olimpiadas de Río de Janeiro 2016 sin protecciones en sus cabezas, tras la reunión del comité ejecutivo del Comité Olímpico Internacional (COI) en Lausana respaldando la decisión tomada en 2013 por la Federación Internacional de Boxeo Aficionado (AIBA) que eliminaba el casco protector en categoría masculina, permaneciendo exclusivamente para los combates femeninos y en categoría juvenil.

La polémica fue avivada por los partidarios de la retirada del casco después de analizar las paradas en los combates por propuesta arbitral, comparando las World Series of Boxing (WSB) dependientes de la federación amateur, pero con un reglamento parecido al profesional, donde se boxea siempre sin protectores. Simultáneamente, los expertos examinaron las grabaciones de los Campeonatos del Mundo de boxeo aficionado de los años 2009, 2011, 2013 y 2015. En los dos primeros, los combates se realizaron con casco. En los siguientes, los boxeadores no llevaron casco protector ${ }^{8}$.

Las interrupciones de los combates se redujeron un $43 \%$ cuando los púgiles no usaron cascos. En el campeonato de 2015, que tuvo lugar en Doha (Catar), los impactos en la cabeza se redujeron un $16 \%$. Más de un $50 \%$ de los golpes recibidos con riesgo de lesión (neurológica o facial) fueron en zonas desprotegidas por el casco.

Los críticos de estos estudios defienden todo lo contrario. Como el Doctor Paul McCrory ${ }^{9}$, neurólogo de la Universidad de Melbourne (Australia) o el bioingeniero médico Andrew Mclntosh, de la Universidad de Monash en Melbourne, que desarrolló un mecanismo simulador de los golpes de un boxeador contra un maniquí con las características anatómicas del cuello y la cabeza humanas, protegido con un casco aprobado por la AIBA. Los resultados demostraron que el casco reducía los impactos lineales y los que provocaban la rotación del cuello.

Las féminas han seguido llevando casco. En un estudio retrospectivo realizado en Italia ${ }^{10}$ en el bienio 2002-2003, referente a la práctica del boxeo femenino, se describieron lesiones en el 3\% de los casos aproximadamente, sobre todo faciales, epistaxis y esguinces en las manos. La desviación del septo nasal fue bastante común (68\%). Tan sólo 1 de las 645 boxeadoras evaluadas necesitó exámenes neurológicos más precisos tras presentar alteraciones electroencefalográficas persistentes a los seis meses. La RNM fue normal y se le permitió regresar a la competición cuando el EEG retornó a la normalidad y desaparecieron los síntomas clínicos.

En el boxeo se producen diferentes combinaciones de golpes que van desde el impacto lineal directo, pasando por la hiperextensión de la columna cervical, hasta la rotación de la cabeza en trayectoria oblicuas.

En cada golpe intervienen dos tipos de fuerzas:

a. La generada por el puñetazo.

b. La resistencia que la cabeza opone al golpe.

Al chocar las dos masas, éstas se deforman; mientras la cabeza se acelera, el puño se ve frenado por la cabeza. Dentro del cráneo, el encéfalo se desplaza hacia delante y hacia atrás, debido al impacto y a la inercia. La distancia entre el encéfalo y el cráneo se reduce, incrementándose la presión intracraneal. Tras el impacto, el cráneo se desplaza con mayor rapidez que el encéfalo, provocando una distensión de las venas y los senos de la duramadre, lo que puede ocasionar hemorragias subdurales.

Tradicionalmente se pensaba que la encefalopatía pugilística crónica estaba causada por hemorragias petequiales múltiples causadas por los traumatismos encefálicos. Pero según Friedrich Unterharnscheidt, autor del mayor tratado sobre aspectos médicos del boxeo ${ }^{11}$, los cambios producidos en los cerebros con demencia pugilística son de tipo isquémico, con destrucción neuronal y proliferación de las células de la glía, junto al desarrollo de placas seniles semejantes a las del Alzheimer.

En 1973, el neurólogo británico John Arthur Nicholas Corsellis (1915-1994) publicó The aftermath of boxing $^{12}$, un estudio que valoraba el encéfalo de 15 boxeadores retirados junto a una detallada retrospectiva de sus vidas, identificando un patrón cerebral típico de la demencia pugilística. En aquellos cerebelos desaparecía el $50 \%$ de las células de Purkinje, tratándose de lesiones diferente a las desarrolladas en otras patologías atróficas neurodegenerativas. 4 púgiles de esta serie fueron diagnosticados de síndrome parkinsoniano, detectándose en ellos una pérdida notable (incluso total) de las células pigmentarias de la sustancia negra.

El Doctor Corsellis también identificó una degeneración neurofibrilar difusa en la corteza cerebral y en el tronco encefálico, con ausencia de placas, detalle diferenciador con la enfermedad de Alzheimer, en la que existe una profusión de placas y de ovillos neurofibrilares. 
La encefalopatía pugilística crónica puede ser detectada a partir de los 30-60 combates. La tolerancia a los golpes va disminuyendo. Los allegados perciben mermas en la capacidad de atención, concentración y memoria; el lenguaje se retarda y se asemeja al de una persona embriagada.

Desde 1951 a 1990 el Doctor Corsellis seleccionó meticulosamente 8500 cerebros, de los cuales 3000 constituyen una particular colección albergada en el Hospital Psiquiátrico de Duffel (Bélgica). Cada ejemplar está acompañado de un historial médico completo y actualizado hasta el día del fallecimiento del paciente. Todos estos cerebros estuvieron a punto de desaparecer como consecuencia de la presión urbanística londinense.

En 1969, el Doctor Anthony H. Roberts publicó su monografía Brain damage in boxers: study of the prevalence of traumatic encephalopathy among ex-professional boxers ${ }^{13}$. Las investigaciones se llevaron a cabo con un grupo de 250 boxeadores federados en Gran Bretaña, de los cuales un $17 \%$ presentaba signos clínicos de lesiones neurológicas atribuibles a la práctica deportiva, predominando los trastornos cerebelosos, síntomas extrapiramidales y deterioro cognitivo.

En 1984, el Doctor Ira R. Casson y su equipo, dependientes del servicio de Neurología del Long Island Jewish - Hillside Medical Center in Jamaica (Queens Nueva York), detectaron evidencia de daño cerebral en 13 de los 15 boxeadores analizados en su serie, una certeza superior a los estudios anteriores, independientemente de si se encontraban en activo o retirados ${ }^{14}$. Sin embargo, en La verdad duele (2015) de Peter Landesman, el Doctor Casson aparece en una entrevista televisiva en calidad de director del equipo médico de la $\mathrm{NFL}$, minimizando los riesgos de las conmociones cerebrales en los jugadores profesionales, mientras las imágenes repasan todos los artículos publicados por el Comité especial de la NFL15.

En 1990, el Doctor G.W. Roberts y sus colaboradores publicaron un artículo titulado The occult aftermath of boxing ${ }^{16}$, retomando los casos estudiados anteriormente por el Doctor Corsellis, y empleando ahora métodos inmunohistoquímicos y la elevación de un anticuerpo específico frente a la proteína beta presente en las placas de la enfermedad de Alzheimer. Sus hallazgos reflejaron la evidencia de extensos depósitos inmunoreactivos de proteína beta en placas en todos los casos de demencia pugilística con formación de sustancias de ovillos neurofibrilares. Estas placas difusas no podían visualizarse con la tinción de Rojo Congo. El grado de depósito de proteína beta fue semejante al observado en los casos de Alzheimer.

A la vista de estos hallazgos, el Doctor Roberts y sus colaboradores concluyeron que la descripción neuropatológica de la demencia pugilística (ovillos sin placas) debe modificarse reconociendo la importante presencia de depósitos de placas de proteína beta. Estudios epidemiológicos han demostrado que las lesiones en la cabeza representan un factor de riesgo para la enfermedad de Alzheimer. Es posible que la demencia pugilística y esta patología neurodegenerativa compartan determinados mecanismos patológicos comunes, encaminados a la formación de placas y ovillos.

En 2005, el Doctor Gregory H. Bledsoe y su equipo del Departamento de Emergencias Médicas de la Facultad de Medicina de la Universidad Johns Hopkins de Baltimore (Maryland-Estados Unidos), analizaron los resultados de 524 combates de boxeo disputados por púgiles profesionales en el estado de Nevada (Estados Unidos), entre septiembre de 2001 y marzo de 2003. Las heridas faciales representaron el $51 \%$ de las lesiones reportadas, seguidas por lesiones de las manos (17\%), traumatismos oculares (14\%) y nasales (5\%).

Estos especialistas comunicaron además un riesgo aproximado de 17 lesiones por boxeador por cada 100 combates disputados. En otras palabras, el riesgo fue de 3.4 por cada asalto. Los perdedores de los combates duplicaron el riesgo personal de lesiones respecto de los vencedores. Los derrotados por KO padecieron el doble de lesiones que los perdedores por puntos. Sin embargo, no se encontró relación directa entre la frecuencia de los traumatismos con el peso y la edad de los púgiles.

\section{Cine y boxeo}

La penosa realidad de los boxeadores veteranos castigados por los destrozos causados por infinidad de combates durante sus dilatadas carreras profesionales ha sido llevada a las pantallas del cine y la televisión en múltiples ocasiones. La serie Requiem for a Heavyweight (TV) (1956) de Ralph Nelson y Alvin Rakoff, con guión de Rod Serling para la antología Playhouse 90 que la CBS mantuvo en antena entre 1956 y 1960 (133 episodios de 60 minutos cada uno), representa un buen ejemplo de ello.

Así, el boxeador Harlan Mountain McClintock (Jack Palance), superviviente en más de 100 combates, se ve abocado a colgar los guantes tras 14 años de trayectoria deportiva. Hostigado por los golpes y deteriorado por 
el paso del tiempo, deberá enfrentarse al descarado intento de explotación por parte de un promotor sin escrúpulos, mientras trata de aferrase a su propia autoestima.

La productiva factoría de la CBS sirvió de banco de pruebas para directores como John Frankenheimer, Robert Mulligan, Arthur Penn y Franklin J. Schaffner, guionistas de la talla del anteriormente mencionado Rod Serling, Arthur Hailey o Aaron Spelling, así como los célebres compositores Jerry Goldsmith y John Williams.

En una de las primeras escenas del episodio protagonizado por Jack Palance, el actor y luchador profesional Maurice Tillet realiza una aparición fugaz entre el público que acompaña por los pasillos al púgil vencedor. La descomunal figura de El Angel Francés quizás fue la fuente de inspiración para el bonachón protagonista de Shrek (2001) de Andrew-Vicky Jenson.

Con el mismo título, Réquiem por un campeón / Requiem for a Heavyweight (1962) de Ralph Nelson saltó a la gran pantalla, con el polifacético Anthony Quinn como el curtido y sonado boxeador Louis Mountain Rivera, y Jackie Wilson en el papel del manager Maish Rennick. Al inicio de este film, Mountain Rivera cae noqueado en el séptimo asalto de un combate. El médico que le examina sobre el cuadrilátero le comunica a Maish Renninck que la carrera competitiva de su maltratado veterano discípulo ha finalizado. Mientras el boxeador trata de recuperar la consciencia, una imagen neblinosa nos desvela quién es el causante de su derrota, un joven y atlético muchacho de apenas 20 años, entonces conocido como Cassius Clay (posteriormente Muhammad Ali).

Precisamente en 1964, ese jovencísimo Cassius Clay arrebataba a Sonny Liston la corona mundial de los pesos pesados por abandono en el 7으 asalto. En el combate de revancha Clay venció de nuevo, pero esta vez en el primer asalto. Para conseguirlo, empleó el famoso "gancho fantasma", un golpe sorpresivo de tal rapidez que todo el mundo pensó que realmente Liston se había tirado a la lona. El gancho fantasma / Phantom Punch (2008) de Robert Towsend es una película que narra la vida del malogrado Sonny Liston (1932-1970), encarnado para la ocasión por el corpulento actor Ving Rames. La cinta se pasea por su ascensión desde la más absoluta pobreza, su paso por la cárcel, hasta su triunfo como campeón mundial de los pesos pesados tras derrotar a Floyd Patterson.

Las desventuras de antiguos campeones que retornan a los cuadriláteros para reverdecer viejas glorias son una constante en el género cinematográfico boxístico, historias de superación personal como El Campeón / The Champ (1931) de King Vidor, en la que el púgil Andy Purcell (Wallace Beary), hundido en la desidia y ahogado por el alcohol, intenta proporcionarle a su hijo una vida mejor. Una versión más moderna de la misma película es Campeón / The Champ (1979) de Franco Zeffirelli, protagonizada por Jon Voigt, Faye Dunaway y Ricky Schroeder.

En la sensacional Nadie puede vencerme o Combate trucado / The Set-Up (1949) de Robert Wise, el curtido boxeador Stoker Thompson (Robert Ryan) es un perdedor que trata de redimirse venciendo al joven campeón Tiger Nelson (Hal Baylor) en una pelea amañada que terminará enfrentándole directamente con la mafia.

El auge y la posterior caída del púgil Rodolfo Casanova inspiró el guión de Campeón sin corona (1946) de Alejandro Galindo, un melodrama mejicano sobre las tribulaciones de Roberto El Kid Terranova (David Silva) y su imparable ascenso desde las peleas callejeras hasta los cuadriláteros profesionales. Años más tarde, la cinematografía mejicana se centró nuevamente en la trayectoria

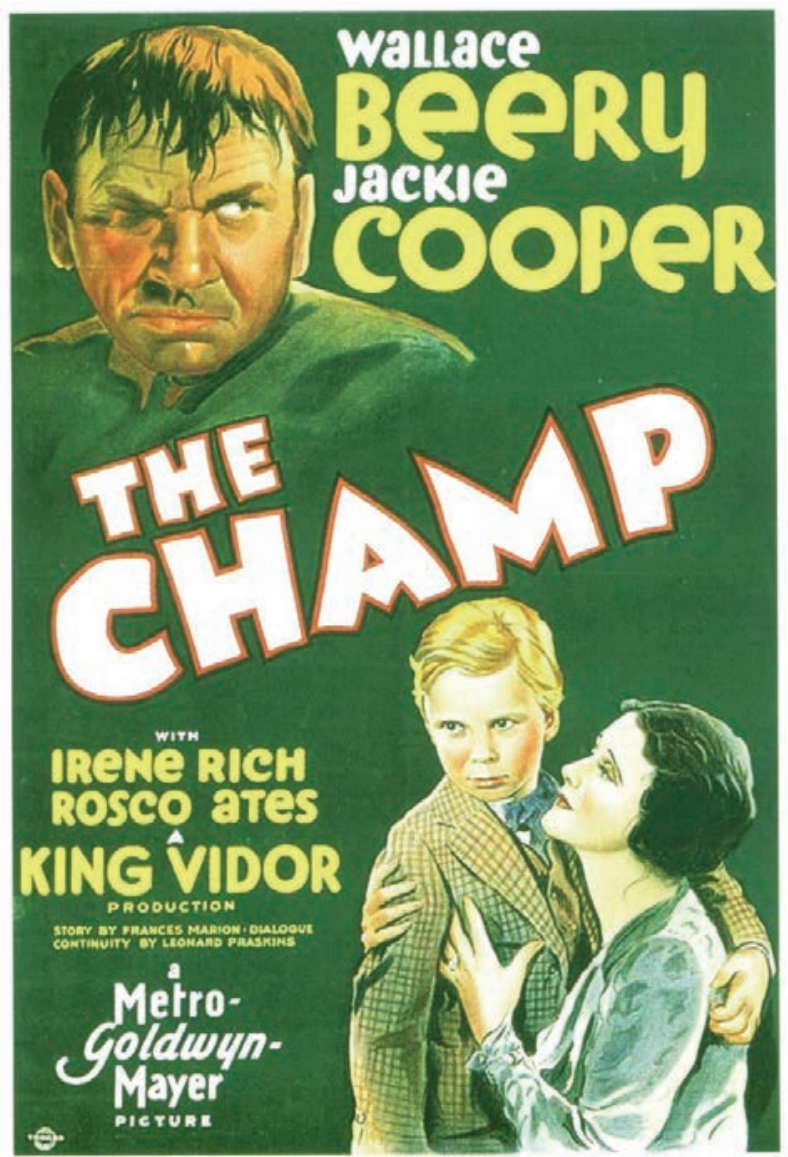


deportiva de otro joven boxeador formado en un gimnasio de barrio, empeñado en triunfar como profesional para así poder casarse con su novia, la cantante estelar de un club nocturno. La película en cuestión es Campeón de barrio (Su última canción) (1964) de Rafael Baledón.

El púgil italiano Primo Carnera, 2.05 metros de estatura y 120 kilos de peso, consiguió en 1933 ser campeón mundial de los pesos pesados. Se interpretó a sí mismo en El boxeador y la dama / The Prizefighter and the Lady (1933) de W.S. Van Dyke y Howard Hawks. Su azarosa carrera deportiva inspiró el personaje de Toro Moreno (Mike Lane) en Más dura será la caída / The Harder They Fall (1956) de Mark Robson, así como el héroe del comic Dick Fulmine.

El 10 de febrero de 1933, Carnera noqueó a Ernie Schaaf durante el 13ㅇa asalto en el combate disputado en el mítico Madison Square Garden de Nueva York. Días antes, el todavía vigente campeón de la Marina estadounidense había sido duramente castigado en otro combate contra Max Baer, postrer campeón del mundo de los pesos pesados en 1934, del que no se habría recuperado adecuadamente. El púgil derrotado entró en coma, falleciendo en el hospital pocos días después.

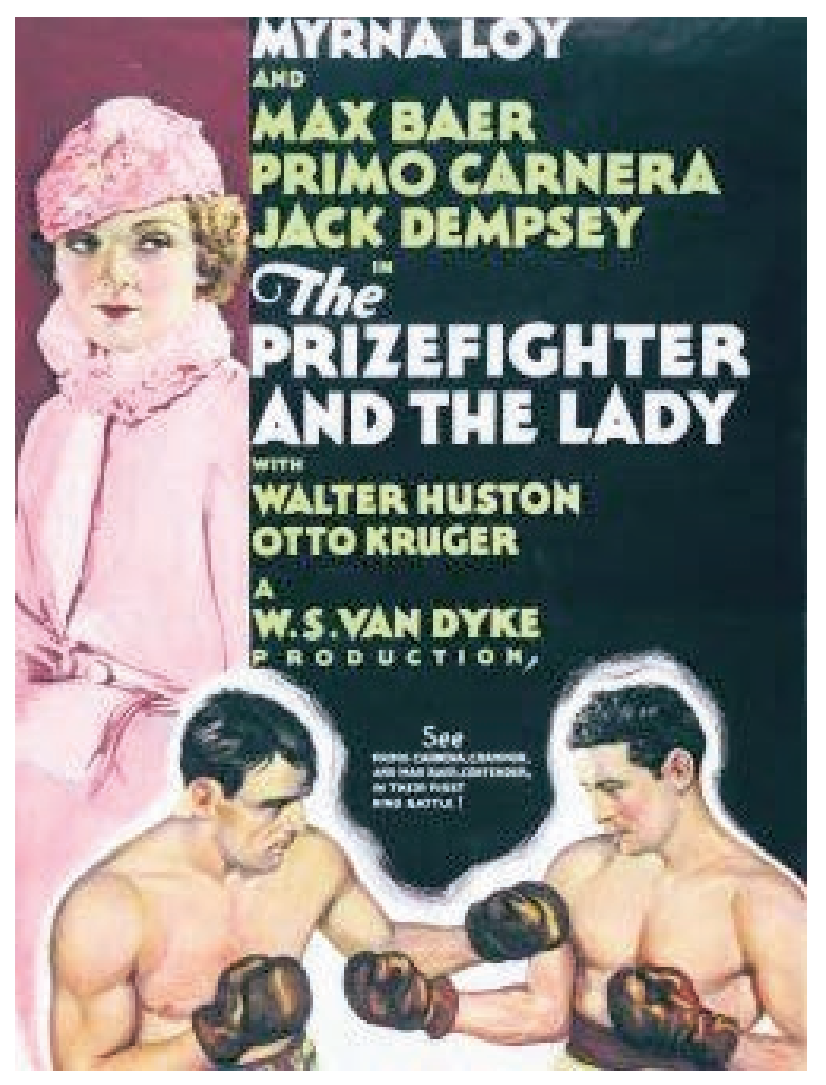

Más historias cinematográficas de perdedores y fracasados. Sería un error imperdonable considerar Fat City, ciudad dorada / Fat City (1972) de John Huston una obra menor en la dilatada carrera del cineasta norteamericano. Este excelente drama de malogrados boxeadores, inspirado en la novela homónima de Leonard Gardner, nos presenta el encontronazo entre Tully (Stacey Keach), un púgil veterano en el declive de su decadente existencia, y Ernie (Jeff Bridges), el ilusionado novato que espera abrirse paso en el mundo de las cuatro cuerdas.

Al respeto, Redención / Southpaw (2015) de Antoine Fuqua, representa una de las últimas historias de liberación profesional llevada a las pantallas cinematográficas. Para la ocasión, Jake Gyllenhaal llevó a cabo un excepcional método de alimentación y entrenamiento para caracterizarse como Billy Hope, un boxeador que busca redimirse de su pasado. El polifacético actor se entrenó en el emblemático Church Gym de Las Vegas (Nevada - Estados Unidos), el mismo escenario donde el campeonísimo Floyd Mayweather preparó sus más exitosos combates. Gyllenhaal llegó a engordar 7 kilos de pura masa musuclar, realizando 2000 abdominales diarios en sesiones de 1000 ejercicios por las mañanas y 1000 por las tardes, durante 6 horas de intensos entrenamientos bajo la atenta supervisión profesional de Terry Claybon.

\section{La verdad duele y el doctor Bennet Ifeakandu Omalu}

En La verdad duele (2015) de Peter Landesman, el encargado de darle vida al Doctor Omalu fue el popular actor Will Smith, acompañado por la actriz británica Gugu Mbatha-Ray (hija real de un médico y una enfermera) en el papel de Prema Mutiso (la esposa de Omalu), Alec Baldwin como el Doctor Julian Bailes y Albert Brooks como el Doctor Cyril Wecht.

El Doctor Omalu nació en septiembre de 1968 en Nnokwa (Nigeria). Fue el sexto de siete hermanos, en el seno de una familia constituida por un ingeniero civil y una costurera. Tras licenciarse en su país en 1990, trabajó como médico interno en el Hospital Universitario de Jos (Nigeria). En 1994 se trasladó a la Universidad de Washington (Estados Unidos).

El interés por la patología data de su etapa como residente en el Harlem Hospital Center, dependiente de la Universidad de Columbia (Nueva York). En 1999 se instala en Pittsburg para formarse con el eminente patólogo Cyril Wecht, en la oficina del forense del condado de Allegheny. Ésta es la época en la que se desarrolla la película. 
Un apunte cinéfilo. En el condado de Allegheny se encuentra la pequeña ciudad de Clairton, una de las localizaciones de El cazador / The Deer Hunter (1978) de Michael Cimino, el decadente escenario de la antaño pujante industria norteamericana del acero.

La historia del Doctor Omalu y su esposa Prema Mutiso se viene repitiendo durante décadas desde la constitución de los Estados Unidos: millones de personas a la procura del llamado sueño americano. Pero en este caso, los inmigrantes no proceden de Italia, Irlanda o Centro Europa. Tampoco son afroamericanos descendientes de los esclavos emancipados que en su día fueron brutalmente arrancados de sus orígenes. Se trata de inmigrantes altamente cualificados, un médico y una enfermera, que dejaron atrás sus patrias deseando convertirse en ciudadanos de pleno derecho en la denominada tierra de las oportunidades.

Estudioso, perseverante e incansable, el Doctor Omalu completó su formación en la Universidad de Pittsburg, culminado con una beca de investigación en Neuropatología en 2002, además de sendos másteres en Salud Pública y Epidemiología en 2004.

Casualmente, en septiembre de 2002, al Doctor Omalu le tocó practicar la autopsia a Mike Webster (David Morse), la malograda estrella de los Pittsburg Steelers, tal vez el mejor center en la historia de la NFL, fallecido a los 50 años de edad tras 12 años de retiro. Jugó 245 partidos en 17 temporadas, 110 consecutivos durante 10 campeonatos. Su historial clínico reflejaba frecuentes episodios de humor alterado, paranoia e intentos de suicidio. Las contusiones cerebrales múltiples padecidas a lo largo de su dilatada carrera deportiva pudieron dañar sus lóbulos frontales, provocándole una evidente disfunción cognitiva.

En un cerebro aparentemente normal, las preparaciones histológicas desvelaron antiguas hemorragias, deterioro vascular y daños neuronales específicos. Mediante técnicas inmunohistoquímicas, el Doctor Omalu descubrió también en el cerebro de Mike Webster un inusitado acúmulo de agregados de proteínas tau, hallazgo que le hizo sospechar que podría encontrarse ante un caso similar a los descritos como demencias pugilísticas en décadas anteriores.

En determinadas circunstancias, las proteínas tau tienden a acumularse y formar fibrillas que dañan las neuronas presentes en áreas cerebrales muy sensibles y específicas, relacionadas con el humor y las emociones. Dichas proteínas son las encargadas de ensamblar el citoesqueleto neuronal: si se producen aglomeraciones, la arquitectura celular colapsa y se interrumpe el funcionamiento neurológico.

La acumulación de proteínas tau es común en los cerebros de los pacientes con Alzheimer. Mike Webster y otros compañeros suyos fallecieron relativamente jóvenes, entre los 45 y los 50 años; la cantidad de proteínas tau en sus cerebros era semejante a la detectada en personas con Alzheimer avanzado.

Acompañado por su jefe, el Doctor Wecht, y tras confirmar sus investigaciones junto al célebre neurólogo Steven DeKosky (Eddie Marsan), el patólogo Ron Hamilton (Stephen Moyer) y el epidemiólogo Ryan L. Minter, el Doctor Omalu consiguió publicar sus hallazgos en la revista Neurosurgery ${ }^{18}$. Desde ese momento, se desató un intenso conflicto con la todopoderosa NFL.

En una peculiar escena de la película contemplamos como el Doctor Omalu posee un televisor que apenas enciende. Lo hace porque según él en Estados Unidos todo el mundo debe tener uno de esos aparatos, una cuestión de prestigio social. Pero pronto descubrirá en la televisión un valioso aliado a la hora de estudiar los traumatismos en el futbol profesional americano.

Los expertos habían descrito dos tipos de síndromes en esta práctica deportiva, que probablemente contribuyeron a empeorar todavía más la encefalopatía crónica de los jugadores afectados:

a. El síndrome postconmocional, con la presencia de 3 ó más síntomas tras una conmoción cerebral, durante un período prolongado (mayor de 3 meses), diagnosticado por las alteraciones de la atención y la memoria. Puede afectar al $15 \%$ de los sujetos que han padecido una conmoción cerebral.

b. El síndrome del segundo impacto, que acontece cuando un jugador padece una segunda conmoción cerebral sin apenas haberse recuperado completamente de la primera. En un partido de fútbol americano pueden suceder varios impactos de menor magnitud, sin pérdida de conciencia. Sufrir una conmoción cerebral multiplica por 5 el riesgo de padecer una segunda. Conmociones sucesivas incrementan el riesgo de un edema o una hemorragia cerebral más graves.

En una escena concreta de la película, el Doctor Julian Bailes (Alec Baldwin) se arrepiente de haber devuelto al campo a jugadores que habían sufrido conmociones cerebrales. Para su rápida recuperación, los 
cuadros médicos se empleaban a fondo: vendas, jeringas, potentes analgésicos como Vicodin ${ }^{\circledR}$ (hidrocodona, la droga a la que se enganchó el popular Doctor House), Dolodol $^{\circledR}$ (hidrocloruro de tramadol), Percocet $^{\circledR}$ (combinación de paracetamol y oxicodona), anestésicos como lidocaína y antidepresivos como Lexapro ${ }^{\circledR}$ (escitalopram) o Zoloft ${ }^{\circledR}$ (sertralina). Un auténtico vademecum.

Desde 1967, los Pittsburg Steelers ganaron la Super Bowl en 6 ocasiones, convirtiéndose en el equipo más galardonado con tan codiciado campeonato; cayeron derrotados en otras 2 ocasiones en las que también alcanzaron la final. Hasta el año 2000 jugaron en el coqueto Three Rivers Stadium, en la confluencia de los ríos Monongahela, Allegheny y Ohio. Demolido en el año 2001, a partir de entonces sus encuentros se celebraron en el Heinz Field, cuya construcción costó 281 millones de dólares, mientras en la ciudad se cerraban varias escuelas y centros sanitarios.

El nexo entre la antaño pujante capital del acero y el futbol americano es tan estrecho, y los recursos económicos generados de tal magnitud, que fácilmente podemos hacernos una idea de los que representaron las investigaciones del Doctor Omalu en su entorno social y profesional.

\section{El caso Mike Webster}

1.90 metros de estatura y 130 kilos de peso. Repasando su trayectoria deportiva, entre 1974 y 1990 ocupó la posición de centro (una de las más castigadas en el futbol profesional americano) en los Pittsburg Steelers y en los Kansas City Chiefs, consiguiendo el campeonato de la Super Bowl en 4 ocasiones. Por sus méritos deportivos fue miembro del Salón de la Fama de la NFL.

Oficialmente, los Steelers anunciaron que el deceso de Mike Webster fue provocado por un infarto de miocardio, si bien la causa real de su muerte nunca llegó a ser pública, por estricto deseo de sus familiares. Arruinado y abandonado por sus seres más queridos, la película nos muestra a la figura retirada de los Steelers sobreviviendo en una destartalada camioneta, esnifando pegamento, consumiendo drogas y autolesionándose.

Sumido en la absoluta indigencia, Webster recibe la visita de su antiguo compañero Justin Strzelczyk (Matthew Willig), que le confiesa sus temores porque también ha comenzado a perder la memoria y a comportarse violentamente. El actor Matthew Willig compitió como profesional durante 14 temporadas en 6 equipos diferentes de la NFL, llegando a participar en dos finales de la Super Bowl, venciendo en una (con los St. Louis Rams) y perdiendo otra (con los Carolina Panthers).

Mike Webster fue atendido por el Doctor Julian Bailes (Alec Baldwin), antiguo responsable de los servicios médicos de los Pittsburg Steelers. En su desesperación le confiesa consumir habitualmente Ritalin ${ }^{\circledR}$ (metilfenidato), Dexedrina ${ }^{\circledR}$ (dextroanfetamina) y Super Glue $^{\circledR}$ (cianoacrilato). Víctima de un insomnio pertinaz, Webster incluso llega a aplicarse descargas con una pistola Taser que le provoca la inconsciencia durante largos períodos de tiempo. Para calmar su agitación, el médico le administra una inyección de Haldol $^{\circledR}$ (haloperidol).

Mientras aguarda su turno en la consulta del médico, el futbolista retirado observa cómo chocan entre si las bolas de acero de un péndulo de Newton, la triste metáfora de su vida deportiva. Sobre la mesa del despacho del Doctor Bailes reposa el cráneo de una pequeña ave, probablemente un pájaro carpintero, detalle que nos da a entender que el especialista ya era buen conocedor del mecanismo evolutivo de esta especie para garantizarle la amortiguación craneal ante los reiterados impactos contra los árboles, y que el propio Doctor Omalu expondría en una secuencia posterior a sus colegas, refiriéndose específicamente a estas aves:

a. El alcatraz de El Cabo, ave buceadora capaz de realizar picados contra el mar a $120 \mathrm{Km} / \mathrm{hora}$.

b. El pájaro carpintero, que picotea la madera 16 veces por segundo. Su cabeza se mueve a 6 metros/segundo, siendo capaces de absorber una

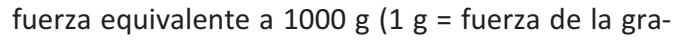
vedad), golpeando el tronco de un árbol 12000 veces al día, 85 millones de veces a lo largo de su existencia. Su hueso hioides, y no su lengua como se menciona en la película, tiene forma de herradura y es inusitadamente largo, enrollándose dentro del cráneo a modo de cinturón de seguridad. Sus huesos craneales son esponjosos, capaces de absorber los impactos. En España, los pájaros carpinteros consiguen taladrar túneles de $20 \mathrm{~cm}$ de largo y 15 $\mathrm{cm}$ de ancho, tarea que puede llevarles entre 1 y 3 semanas, dependiendo de la dureza de la madera.

El Doctor Julian Bailes fue Presidente del Departamento de Neurocirugía del North Shore University Health System y co-director del North Shore Neurological Institute. En la ficción cinematográfica (Alec Baldwin) fue el primer especialista que confirmó las sospechas del Doctor Omalu, pues este neurocirujano conocía de primera mano los efectos provocados por los traumatismos cerebrales en los jugadores profesionales de 
futbol americano como antiguo integrante del cuerpo médico de los Steelers de Pittsburg.

Él mismo le desvela a Omalu que la NFL ya había realizado investigaciones sobre las conmociones cerebrales y los traumatismos en sus profesionales. La realidad, que no se nos muestra en La verdad duele (2015) de Peter Landesman es que, desde 1982, a raíz de las negociaciones suscitadas por una huelga de jugadores, saltó a la palestra la desafortunada historia de Doug Kotar (19511983), el pequeño y correoso running back de los New York Giants. Aquejado de constantes e insoportables cefaleas, en realidad padecía una neoplasia cerebral irresecable. La NFL se negó a reconocer la relación entre dicha patología y la práctica deportiva profesional, por lo que le denegó a Kotar la cobertura de sus gastos médicos. Este jugador falleció en el Hospital Montefiore de Pittsburgi9.

En la película, el Doctor Bailes le entrega al Doctor Omalu un ejemplar del estudio de Elliot J. Pellman publicado en octubre de $2003^{20}$, el documento en el que se basó la NFL para establecer sus directrices respecto a las conmociones cerebrales. En una de sus conclusiones solicitaba nuevas pruebas para valorar el rendimiento de los cascos protectores en la reducción de los riesgos conmocionales, a su vez involucrados en la biomecánica de las lesiones de elevada velocidad y larga duración.

Según Bailes, los investigadores habían empleado monos a los que les habían colocado cascos, cerdos, perros y cadáveres lanzados por el hueco de un ascensor, así como maniquíes especiales (dummies). La verdad es que el equipo de Pellman analizó las grabaciones en video de 182 bloqueos especialmente traumáticos ocurridos entre 1996 y 2001 correspondientes a encuentros de la NFL, para intentar reproducir los impactos en el laboratorio empleando dummies.

Para la evaluación del estudio, la NFL creó la Comisión de Lesiones Cerebrales Traumáticas Leves, dirigida por el propio Doctor Pellman (Paul Reiser) y en la que también participó el Doctor Maroon (Arliss Howard). En la película, el primer especialista sale bastante mal parado: Bailes y Omalu se mofan de su especialidad (Reumatología) y de su formación en la Universidad de Guadalajara (Méjico). La realidad es que si bien Pellman obtuvo su licenciatura en la universidad mejicana, su especialización como reumatólogo tuvo lugar en el Hospital Mount Sinai de Long Island (Nueva York), donde además impartió docencia.

Bailes se convirtió en el interlocutor entre Omalu y los especialistas vinculados a la NFL como el Doctor
Maroon, retratado como un villano en la película, aunque en la realidad probablemente mucho menos obstruccionista.

\section{Los deportes de contacto y las conmociones cerebrales}

En los humanos, una conmoción cerebral se produce con impactos de $60 \mathrm{~g}$ o mayores. Los cabezazos que tienen lugar en un partido de futbol americano pueden alcanzar las $60 \mathrm{~g}$.

El piloto Robert Kubica sufrió un brutal impacto mientras disputaba el Gran Premio de Canadá de Fórmula 1 en 2007. Durante apenas 1 milisegundo padeció un pico de 70 g. Su colega Ralf Schumacher resultó prácticamente ileso en un accidente ocurrido en el circuito de Indianapolis (Estados Unidos), llegando a soportar $72 \mathrm{~g}$. En 2003 Kenny Brack, otro piloto que competía en la categoría Indy Car, sobrevivió a un aparatoso accidente con un pico de $214 \mathrm{~g}$ que le provocó varias fracturas (esternal, vertebral y femoral), y un esguince de tobillo. Necesitó 18 meses para recuperarse. El record mundial aguantado por un voluntario fue de $82.6 \mathrm{~g}$ durante 0.04 segundos.

El Doctor John Paul Stapp (1910-1999), cirujano de la fuerza aérea estadounidense, protagonizó en la década de los 40 del pasado siglo XX una serie de experimentos para conocer la magnitud de la fuerza gravitatoria que un humano podía tolerar ${ }^{21}$. En aquel entonces se pensaba que el cuerpo humano solamente podía soportar fuerzas inferiores a 18 g. En abril de 1947, el coronel Stapp comenzó una serie de ensayos en la base aérea de Edwards, en California (Estados Unidos). Empleó un trineo especial que contaba con 6 cohetes a su espalda capaces de ejercer una presión de 13000 kilos. Lo probó sobre una pista de 610 metros que finalizaba en una piscina de frenado. Tras alcanzar una velocidad de casi $700 \mathrm{Km} / \mathrm{hora}$, sobrevivió a una presión de desaceleración de 22 g.

El 10 de diciembre de 1954, aumentó el número de cohetes de su trineo hasta 9, lo que le proporcionó una fuerza de $18000 \mathrm{Kg}$ de empuje y una velocidad de $1000 \mathrm{Km} /$ hora en tan solo 5 segundos, el equivalente de chocar un coche contra una pared a $200 \mathrm{Km} /$ hora.

Gracias a sus investigaciones, comenzaron a realizarse las primeras pruebas de seguridad automovilística con dummies. En 1966, bajo su iniciativa, el presidente Lyndon Johnson confirmó la primera ley que obligaba a instalar cinturones de seguridad en los coches.

En los deportes de contacto, y en el fútbol americano en particular, la desaceleración del cerebro contra 
la parte interna del cráneo produce lesiones en la zona de impacto (lesiones por el golpe), así como en la zona contraria (lesión por contragolpe). Éstas últimas se generan por el desplazamiento encefálico dentro de su envoltura ósea, y pueden ser de rebote (provocada por el impacto directo) y de aceleración - deceleración (cuando la cabeza no golpea contra ningún objeto).

Las contusiones frontales producen lesiones en las superficies orbitarias de los lóbulos frontales y en la parte anterior y basal de los lóbulos temporales, mientras que las contusiones laterales se producen en la convexidad de los hemisferios cerebrales.

En el caso que nos ocupa, el casco protector contribuye a paliar los efectos negativos de los golpes, evitando fracturas craneales, pero su efectividad no es completa. En el fútbol americano, las posibilidades de sufrir una contusión cerebral son elevadas. En un $10 \%$ de los casos con pérdidas de conciencia sobrevenidas. La hospitalización del jugador contusionado es necesaria en el $2.5 \%$ de las ocasiones.

Diversas estimaciones apuntan que cada año se producen 1 millón de contusiones cerebrales en la práctica deportiva estadounidense, si bien en realidad podría tratarse de muchas más porque en gran parte pasan desapercibidas; desafortunadamente sólo quedan registrados aquellos casos que conlleven una pérdida de conciencia, circunstancia que ocurre en el $10 \%$ de las ocasiones.

En la pretemporada y la temporada regulares de 2012-2013, los jugadores de la NFL sufrieron 400 contusiones cerebrales. En algo más de la mitad de las ocasiones, los impactos se produjeron contra los cascos protectores de los rivales. En el $13 \%$ de los casos, contra las rodillas o los pies, en el $12.2 \%$ contra hombros, antebrazos o codos, y en el $10 \%$ contra el propio terreno de juego.

Los síntomas de las contusiones cerebrales son variables:

a. Somáticos: cefalea, cervicalgia, visión borrosa, mareos, trastorno del equilibrio, náuseas y vómitos, hipersensibilidad al ruido o a la luz, fatiga y alteraciones de la coordinación corporal.

b. Cognitivo-conductuales: confusión, pérdida de la concentración, déficit de memoria a corto y largo plazo, desorientación temporal-espacial.

c. Emocionales: ansiedad, nerviosismo, irritabilidad, labilidad emocional, tristeza, trastornos del estado de ánimo.
La mayoría aparecen verazmente reflejados en $L a$ verdad duele (2015) de Peter Landesman, personificados en los diferentes profesionales que van sucumbiendo progresivamente a la enfermedad y la muerte. Cronológicamente, Mike Webster fue el primero, pero no el único.

Los avances tecnológicos en las técnicas de diagnóstico médico por imagen permitirán detectar lesiones patológicas que hasta ahora eran hallazgos post mortem. Un grupo de expertos dirigido por el Doctor Francis X. Conidi, del Florida Center for Headache and Sports Neurology, que además ejerce como docente en la Facultad Estatal de Medicina de Florida en Tallahassee (Estados Unidos), evaluó a 40 futbolistas profesionales retirados, con una edad media de 37 años (27 el más joven y 56 el mayor), mediante técnicas de RNM altamente sensible, conocidas como imágenes de tensor de difusión ${ }^{22}$. Dicha técnica permitió medir la cantidad de deterioro provocado en la sustancia blanca del cerebro, basándose en el movimiento de las moléculas de agua dentro del parénquima cerebral. Presentaron los resultados de su estudio en la 68 Reunión Anual de la Academia Americana de Neurología, que tuvo lugar en Vancouver (Canadá) en 2016, tras conseguir demostrar evidencias objetivas y significativas de lesiones cerebrales traumáticas. En el $30 \%$ de los casos se detectaron disrupciones de los axones neuronales.

Todos los futbolistas llevaban al menos 5 años retirados, con un tiempo medio de práctica deportiva de 7 años. Durante este período, padecieron una media de 8 conmociones cerebrales; cuanto más dilatada fue la carrera profesional, mayor número de daños. Sin embargo, no se encontró relación entre el número de conmociones y la presencia de deterioro neurológico.

Además, algunos de ellos (38\%) aseguraron haber recibido diversos golpes subconcusivos. La traducción clínica fue la siguiente: $50 \%$ con problemas de función ejecutiva, $45 \%$ con deterioro del aprendizaje y la memoria, $42 \%$ con déficit de atención y concentración y $21 \%$ con alteraciones en la percepción y la función conceptual.

Como experto en la materia el Doctor Conidi ha publicado una guía sobre las conmociones cerebrales en el deporte 23 y un comentario sobre lo que los neurólogos deben saber sobre el film La verdad duele (2015) de Peter Landesman ${ }^{24}$. La propia Asociación Americana de Neurología y la Asociación de Futbolistas Profesionales (NFLPA) han aportado información y oferta de recursos destinados a médicos, entrenadores, atletas y familiares respecto a las patologías provocadas por las conmociones cerebrales. 
En la Universidad de Boston, en el año 2008, se fundó el primer banco de cerebros con la finalidad de investigar la encefalopatía crónica traumática en los jugadores profesionales de fútbol americano retirados. En este centro se detectó esta patología en 87 de los 91 cerebros estudiados. De forma similar, existen otros datos contundentes respecto a de este colectivo de deportistas: si la esperanza de vida media de los varones norteamericanos se sitúa en 76 años, en los profesionales de la NFL cae hasta los 57.

El estudio de la Universidad de Boston, el sueño del Doctor Omalu durante la ficción cinematográfica, incluyó 50 expertos de 17 instituciones diferentes, que investigaron a cientos de ex jugadores de la NFL y la NCAA (National Collegiate Athletic Association), con la finalidad de detectar, definir y medir la progresión de la encefalopatía traumática crónica. Además del Doctor Robert Stern, profesor de Neurología y Neurocirugía de la Universidad de Boston, participaron el Doctor Jeffrey Cummings, director de la clínica Lou Ruvo Center for Brain Health de Cleveland, el Doctor Eric Reiman, director ejecutivo del Banner Alzheimer's Institute de Phoenix y la Doctora Martha Shenton, profesora de psiquiatría y radiología de la Universidad de Harvard, además de directora del laboratorio de neuroimágenes psiquiátricas en el Brigham and Women's Hospital de Boston.

La NCAA agrupa a 1281 instituciones, conferencias, organizaciones e individuos organizadores de la mayoría de los programas deportivos universitarios en los Estados Unidos, incluyendo el fútbol americano. Tras afrontar diversas demandas millonarias por parte de los afectados y sus familiares, la NFL reconoció finalmente los posibles vínculos entre la encefalopatía traumática crónica y las conmociones cerebrales provocadas por la práctica del fútbol americano, tanto en jugadores profesionales como amateurs.

En 2012, la NFL concedió una subvención de 20 millones de dólares a la NIH (National Institutes of Health) destinados a proyectos de investigación de la encefalopatía traumática crónica en pacientes vivos, ya que hasta entonces todos los análisis procedían de autopsias. Pero la poderosa institución deportiva no tardó en cambiar de opinión tras conocer que al frente de las investigaciones se situaría al mismísimo Doctor Robert Stern, el responsable de la retirada precoz de Chris Borland, la estrella de los San Francisco 49ers.

Las reticencias de la NFL, personalizadas por el comisionado jefe Roger Goodell (Luke Wilson), economista y exitoso atleta durante su etapa en el instituto, siempre estuvieron presentes. Goodell sucedió al todopoderoso Paul Tagliabue (Dan Ziskie), comisionado jefe entre 1989 y 2006, y socio de la firma internacional de abogados Covington y Burling, fundada en 1919 y la encargada de coordinar a los expertos "independientes" del controvertido Proyecto de Consultores en Tabaco y Ambiente, tras el cual se encontraban reconocidas empresas como Philip Morris y British American Tobacco.

Como breve apunte cinéfilo destacamos que en Gracias por fumar / Thank You For Smoking (2005) de Jason Reitman, el cínico Nick Naylor (Aaron Eckhart) se reunía semanalmente con "los mercaderes de la muerte", un particular y pernicioso equipo constituido por los jefes de prensa de los potentes lobbies de la industria del alcohol, el tabaco y las armas, aliados de reputados bufetes de abogados que tan pronto se encargaban de la defensa de los intereses tabaqueros como de los de la NFL.

En 2015, un estudio independiente (no subvencionado por la NFL) dirigido por Eric Nauman y Thomas Talavage, profesores de ingeniería mecánica-eléctrica y biomédica de la Universidad de Purdue (Indiana) respectivamente, demostró que en el fútbol americano los

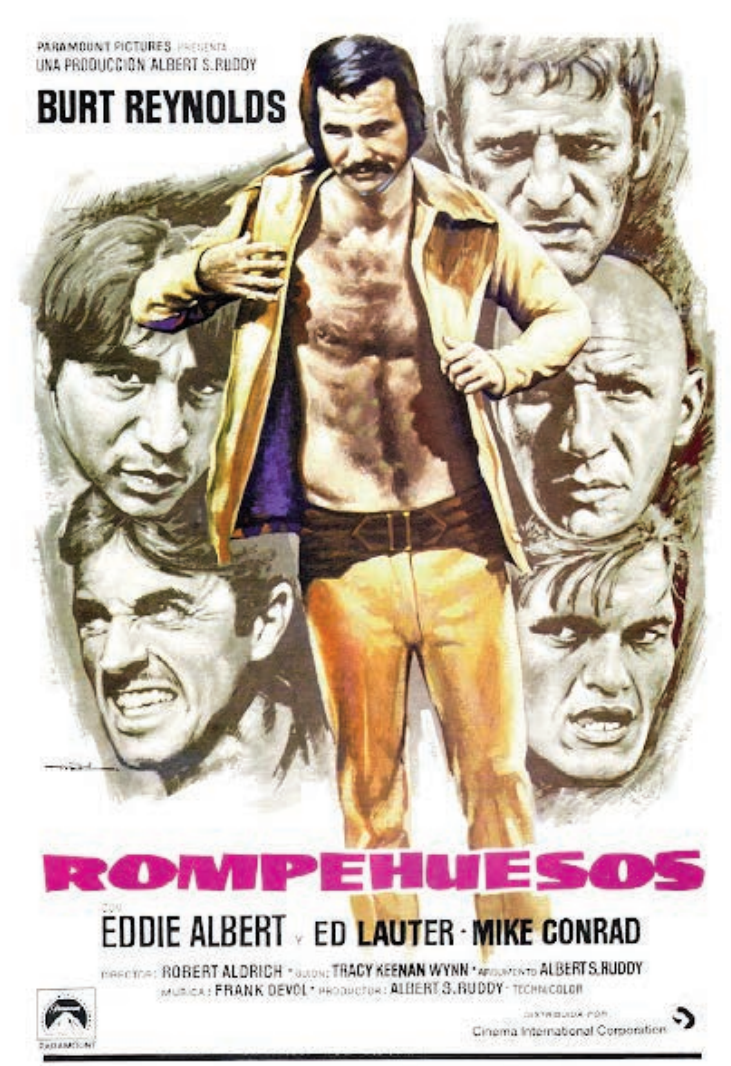


traumatismos craneales repetidos y constantes provocan importantes cambios bioquímicos en el cerebro 25 .

Jeff Miller, vicepresidente para la salud y la seguridad de la NFL, ha llegado a reconocer públicamente que existe un buen número de jugadores retirados diagnosticados de encefalopatía traumática crónica, dando por buenas las investigaciones realizadas por la patóloga Ann McKee de la Universidad de Boston, experta en enfermedades neurodegenerativas y fan incondicional de los Green Bay Packers (Wisconsin), 11 veces campeones de la NFL. La Doctora McKee fue la encargada de analizar el cerebro de Aaron Hernández (1989-2017), el astro procedente de la Universidad de Florida que fichó por los New England Patriots, vencedores de la Super Bowl en 2017. Tras ser juzgado y condenado por asesinato, Hernández se ahorcó en su celda del centro correccional Souza-Baranowski, de Massachusetts.

La familia del malogrado futbolista decidió donar su cerebro para que los especialistas confirmaran el diagnóstico de encefalopatía traumática crónica, debido a la violenta trayectoria de Aaron Hernández durante los últimos años de su existencia, y toda vez que su franquicia le rescindiera por ello un contrato millonario.

Avivando la controversia, en el 2014 el neurólogo estadounidense Jim Andrikopoulos publicó sus opiniones particulares sobre la encefalopatía traumática crónica $^{26}$. Para este especialista, sería un error trasladar a los jugadores y sus familias que las contusiones cerebrales son responsables de las conductas suicidas. Para el Doctor Andrikopoulos existen dos formas clínicas de este síndrome: una en deportistas jóvenes, donde fundamentalmente aparecen trastornos de la conducta y del comportamiento, y otra en los veteranos y ex jugadores, más relacionada con déficits cognitivos. Así se mostraba crítico con los postulados del Soports Legacy Institute (SLI) de Boston, una entidad sin ánimo de lucro fundada en 2007 por el neurólogo Robert Cantu y el ex luchador Chris Nowinski. El especialista había atendido al deportista en su etapa como profesional tras sufrir una conmoción cerebral. En el año 2008, el SLI se asoció con la Facultad de Medicina de Boston, contando con la colaboración del Doctor Stern y la Doctora McKee desde entonces. La idea fundacional del SLI se basó en los trabajos del Doctor Omalu.

Pero no todos los especialistas estuvieron de acuerdo con él desde el principio. Uno de ellos fue el especialista británico Doctor Corsellis, cuyas descripciones neuropatológicas sobre la demencia pugilística diferían de las de Omalu, como tampoco las investigaciones iniciales de la Doctora McKee. Para el Doctor Adrikopoulos, en los 30 años que separan los hallazgos de Corsellis y Omalu, sigue sin existir un patrón neuropatológico claramente distintivo.

El síndrome clínico clásico descrito por el neurólogo británico Macdonald Critchley (1900-1990) era un cuadro parkinsoniano. Todavía hoy en día, su serie de casos es la más numerosa analizada por un mismo profesional. Una década más tarde, A.H. Roberts dirigió el estudio epidemiológico definitivo sobre la demencia pugilística, reclutando al azar a 250 boxeadores que compitieron entre 1922 y 1955 . Para los investigadores estadounidenses, el diagnóstico de la encefalopatía traumática crónica habría de realizarse mediante autopsia. Pero, entonces, ¿por qué nadie ha realizado un estudio como el de Roberts desde 1965, con pacientes vivos?

Para el Doctor Andrikopoulos, desde el SLI se estaría tratando de exportar su modelo etiopatogénico al resto del mundo y disciplinas deportivas de contacto. Así como Chris Nowinski representa en Estados Unidos el rostro de un ex deportista famoso comprometido con la causa, en Gran Bretaña lo sería Jeff Astle, el mítico goleador del West Brownwich Albion, fallecido en 2002 a los 59 años a causa del Alzheimer. El diagnóstico de la autopsia fue modificado a posteriori por el neuropatólogo escocés Willie Stewart, identificándolo con un caso de encefalopatía traumática crónica.

Para aportar un mayor conocimiento en esta patología deportiva, en 2018 se publicaron los resultados de varios estudios basados en las nuevas tecnologías diagnósticas. Por una parte, un equipo multidisciplinar de investigadores canadienses, estadounidenses y alemanes ${ }^{27}$ estudió la implicación de las estructuras límbicas en la patología neurológica de la encefalopatía traumática crónica. Para ello emplearon imágenes de resonancia magnética 3T (RNM 3T) para comparar los volúmenes de la amígdala, el hipocampo y la circunvolución cingulada en un grupo de jugadores de la NFL que presentaban síntomas, frente a un grupo control de 22 individuos sanos.

Además, dentro del grupo de ex jugadores de la NFL, examinaron las estructuras límbicas y el funcionamiento neuroconductual. Se trataba de 86 jugadores retirados con un historial de al menos 12 años de práctica deportiva y al menos 2 años de participación activa en la competición de la NFL, que presentaban déficits cognitivos autopercibidos y alteraciones del comportamiento en los últimos 6 meses. El grupo control estuvo formado por hombres de mediana edad, sin antecedentes de 
lesiones cerebrales traumáticas ni lesiones provocadas por deportes de contacto.

En el grupo de ex profesionales de la NFL, se detectaron volúmenes más reducidos de la amígdala, el hipocampo y el giro cingulado. Además, la reducción bilateral del giro cingulado se asoció a una peor atención y velocidad psicomotora. Un menor volumen del hipocampo derecho se asoció a una peor memoria. Los investigadores concluyeron que el menor volumen de las estructuras límbicas en los ex jugadores de la NFL determina las alteraciones neurocognitivas de la encefalopatía traumática crónica, y además pueden ser biomarcadores potenciales de la neurodegeneración en aquellos deportistas con riesgo de padecerla.

La evaluación neuropsicológica es un medio económico y eficaz para detectar las alteraciones cognitivas de aquellos deportistas víctimas de una conmoción cerebral. Simultáneamente, ha demostrado su utilidad a la hora de evaluar la recuperación de la normalidad neurológica. Por desgracia, solamente aporta información en los casos agudos. Representa una manera objetiva para determinar si un jugador puede o no reiniciar su actividad deportiva, evitando complicaciones posteriores.

Este tipo de valoración es cada vez más frecuente en diversos ámbitos deportivos profesionales, como por ejemplo el fútbol americano y el hockey sobre hielo. Las ligas profesionales (NFL y NHL) la han incorporado a sus programas habituales en la valoración de las conmociones cerebrales.

Sin embargo, para estimar la presencia de efectos crónicos resultan más apropiados los potenciales relacionados a eventos (PRE's), empleados en la monitorización clínica de las conmociones cerebrales y en la recuperación de los deportistas lesionados, como por ejemplo los golpes conmocionales o subconmocionales en los boxeadores.

Por otra parte, el análisis de determinadas proteínas del líquido cefalorraquídeo (LCR) como la tau total, la tau fosforilada y la beta amiloide, puede contribuir a determinar qué tipo de lesiones neurológicas han sido provocadas por traumatismos cerebrales repetidos en la encefalopatía traumática crónica. En la serie estudiada por el grupo del Doctor Stern en la Universidad de Boston ${ }^{28}$, empleando 68 ex futbolistas profesionales de la NFL y 21 controles sanos, una mayor cantidad de traumatismos craneoencefálicos junto a un incremento de la actividad de la microglía fueron relacionados con las mayores concentraciones de proteína tau en el LCR.
Las investigaciones más modernas se centran en el papel que desempeñan determinados biomarcadores a la hora de identificar a los pacientes con posibles lesiones cerebrales tras haber sufrido un traumatismo craneoencefálico leve. Estos marcadores se determinan en la sangre y su valor diagnóstico ahorraría exploraciones radiológicas innecesarias. Investigadores suizos y españoles proponen la combinación de los biomarcadores $\mathrm{H}$ FABP (heart fatty acid binding protein) y GFAp (glial fibriIlary acid protein), que ha demostrado una sensibilidad del $100 \%$ y una especificidad del $46 \%$ a la hora de determinar qué traumatismos craneoencefálicos leves podrían necesitar o no un TAC craneal29.

\section{La lista de Omalu}

Mike Webster fue el primer ex-jugador profesional del fútbol americano investigado por el Doctor Omalu, el inicio de una lista de posibles casos de encefalopatía traumática crónica.

Justin Conrad Strzelczyk (1968-2004) fue el siguiente. En la película somos testigos de su breve y progresiva degradación, y de los conflictos familiares soportados por su esposa Keana (Elizabeth Tullock) y sus pequeños. Diversas lesiones encadenadas en sus piernas y rodillas le obligaron a cancelar sustanciosos contratos con los Steelers. Aficionado a las motos (en la película pilota una Harley Davidson), fracasado en los negocios y con su vida destrozada, Strzelczyk (Matthew Willig) falleció en Herlimer (Nueva York) a los 36 años, después de chocar a $140 \mathrm{Km} /$ hora contra un camión cisterna, mientras huía de la policía conduciendo en sentido contrario por la autopista.

En un principio, se pensó que la causa del accidente de tráfico había sido el consumo de alcohol y otros estupefacientes, si bien todos los análisis toxicológicos resultaron negativos. Su autopsia desveló daños cerebrales compatibles con la práctica deportiva. En el año 2007, la madre de Justin (y no su viuda, como se nos muestra en la película) autorizó que el Doctor Omalu examinara el cerebro de su hijo difunto.

Justin Strzelczyk participó en el video The Lonesome Kicker (1997) de Adam Sandler, acompañado por otros compañeros de los Steelers como Jerome Bettis, Greg Lloyd y Kordell Steart.

Terry Luther Long (1959 - 2005) fue el siguiente de esta hipotética lista. Procedente de la East Carolina University, formó parte de la línea ofensiva de los Pittsburg Steelers durante 8 temporadas. Long se suicidó tras ingerir 
1 galón (3.5 litros) de líquido anticongelante. Falleció en el hospital apenas 5 horas después de haber sido encontrado inconsciente en su domicilio. Su autopsia reveló que padecía una encefalopatía traumática crónica. En 1991, Terry Long había intentado quitarse la vida por haber dado positivo por esteroides anabolizantes en un control de la NFL. En plena controversia por los informes del Doctor Omalu, a Terry Long se le llegaron a practicar 3 autopsias; en la última, la definitiva, se detectaron restos de etilenglicol en orina, un ingrediente básico de los anticongelantes.

Andre M. Waters (1962 - 2002) fue uno de los mejores jugadores defensivos de la NFL. Entre 1984 y 1995 destacó en los Philadelphia Eagles y en los Arizona Cardinals. Se suicidó de un disparo en Tampa (Florida). Su cerebro fue analizado por el Doctor Omalu, que una vez más relacionó los hallazgos neurodegenerativos de la autopsia con los traumatismos craneales recibidos por Waters (Richard T. Jones) a lo largo de su carrera deportiva. Al final de su existencia, este excepcional jugador sobrevivía discapacitado, arruinado y sumido en una profunda depresión. Al margen de sus triunfos como jugador, Andre Waters realizó breves apariciones en Melodía para un asesinato / Fingers (1978) de James Toback y en

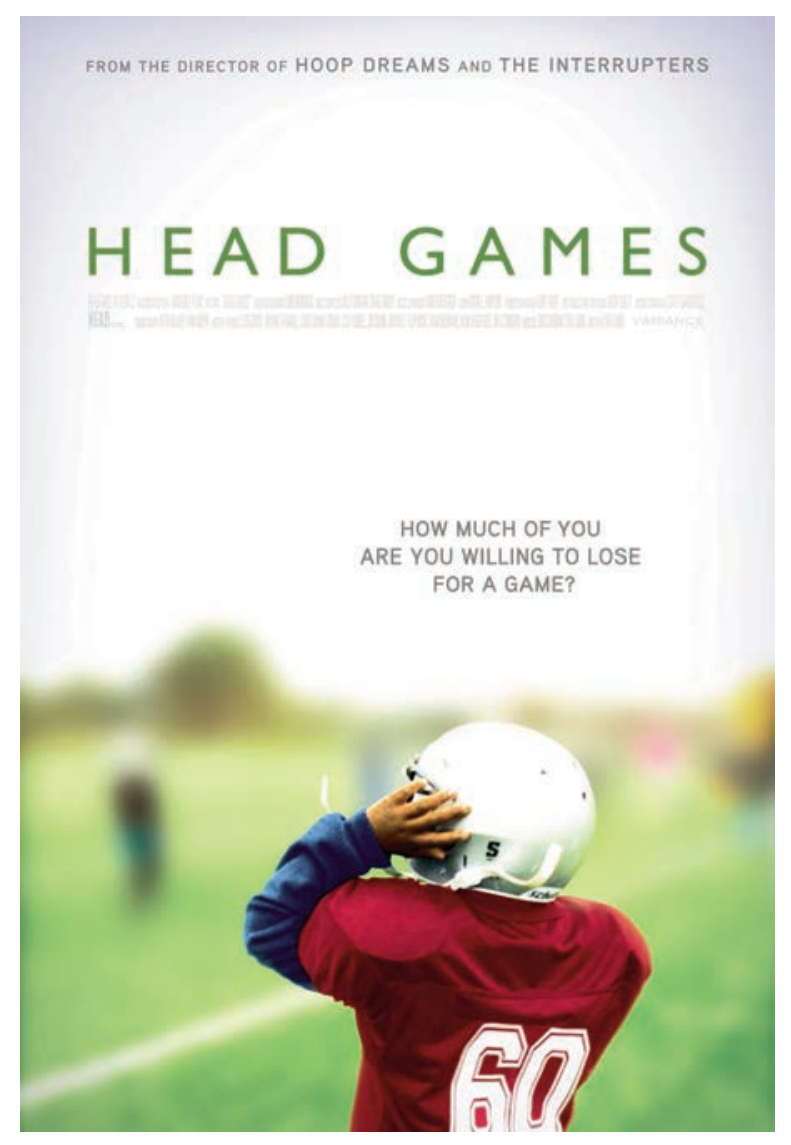

Scarred (1983) de Rosemarie Turko. Al igual que Terry Long y otros futbolistas de la NFL, intervino en el reportaje Head Games (2012) de Steve James, donde el ex profesional y ex luchador Chris Nowinski guía a los espectadores en ese particular periplo sobre las lesiones causadas por los traumatismos deportivos y sus consecuencias.

Ante este nuevo deceso, la NFL continuó demostrando su escepticismo. No todos los especialistas aceptaban las evidencias de Omalu. El Doctor Andrew Tucker, del cuerpo médico de los Baltimore Ravens, alegó que la competición no disponía en aquellos días de una evidencia completa respecto a los trastornos de la salud mental de los profesionales retirados.

El penúltimo de la lista fue David Russell Duerson (1960 - 2011), que compitió con los Chicago Bears, los New York Giants y los Phoenix Cardinals, donde se retiró en 1993. Veterano muy ligado al Comisionados de la NFL, tal y como se constata en la película, su interpretación corrió a cargo del fornido actor británico Adewale Akinnuoye-Agbaje. David Duerson se suicidó mediante un disparo en el pecho. A causa de sus síntomas, poco a poco se fue convenciendo de que padecía una encefalopatía traumática crónica. Por ello, donó su cerebro a la Facultad de Medicina de la Universidad de Boston, para que pudieran confirmar el diagnóstico.

El último de estos malogrados futbolistas fue Junior Seau (1969 - 2012), linebaker retirado en 2009 después de jugar como profesional en los New England Patriots, los San Diego Chargers y los Miami Dolphins. Considerado unos de los mejores jugadores entre los que históricamente disputaron la Super Bowl, puso también final a sus días con un disparo en el tórax. Su autopsia desveló un caso más de encefalopatía traumática crónica.

\section{Referencias}

1. Pérez V. Escándalo en la NFL. ABC.es [Internet]. 19 de agosto de 2012. [Consultado el 1 de julio de 2018].

2. Smith G. Someone To Lean On. Sports Illustrated [Internet]. 16 de diciembre de 1996. [Consultado el 13 de julio de 2018].

3. Peniche-Pérez AA, Méndez-Domínguez N. La verdad Oculta (2015): Una disputa médico-deportiva llevada al cine. Rev Med Cine 2016;12(4): 205-10.

4. Laskas JM. Bennet Omalu, Concussions, and the NFL: How One Doctor Changed Football Forever. Gentlemen's Quartely [Internet]. 14 de septiembre de 2009. [Consultado el 1 de julio de 2018].

5. Martland HS. Punch Drunk. JAMA. 1928; 91 (15): 1103-107.

6. Noonan D. Boxing and the Brain. The New York Times Magazine [Internet]. 12 de junio de 1982. [Consultado el 13 de julio de 2018].

7. Critchley M. Medical aspects of boxing, particulary from a neurological standpoint. Br Med J. 1957; 1(5015): 357-362. [Consultado el 13/07/2018].

8. Loosemore MP, Butler Cf, Khadri, A McDonagh D, Patel VA, Bailes JE. Use of head guards in AIBA boxing tournaments - A cross - sectional observational study. Clin J Sport Med 2017; 27 (1): 86-8.

9. McCrory P, Falvey É, Turner M. Returning to the Golden age of boxing. Br J 
Sports Med 2012; 46(7):459-60

10. Bianco M, Pannozzo A, Fabbricatore C, Sanna N, Moscetti M, Palmieri V, et al. Medical survey of female boxing in Italy in 2002-2003. Br J Sports Med. 2005;39(8):532-6.

11. Unterharnscheidt F, Taylor-Unterharnscheidt J. Boxing, Medical Aspects. London: Academic Press; 2003.

12. Corsellis JA, Bruton CJ, Freeman-Browne D. The aftermath of boxing. Psychol Med. 1973;3(3):270-303.

13. Roberts AH. Brain damage in boxers: a study of the prevalence of traumatic encepahlopathy among ex-professional boxers. London: Pitman Medical \& Scientific Publishing Co., Ltd.; 1969.

14. Casson IR, Siegel O, Sham R, Campbell EA, Tarlau M, DiDomenico A. Brain damage in modern Boxers. JAMA. 1984;251(20):2663-7.

15. Pellman EJ, Viano DC. Concussion in profesional football: summary of the research condcuted by The National Football League's Committee on mild traumatic brain injury. Neurosurg Focus. 2006;21(4):E12.

16. Roberts GW, Allsop D, Bruton C. The occult aftermath of boxing. J Neurol Neurosurg Psychiatry. 1990; 53(5): 373-8.

17. Bledsoe GH, Li G, Levy F. Injury risk in profesional boxing. South Med J. 2005;98(10):994-8.

18. Omalu BI, DeKosky ST, Minster RL, Kamboh MI, Hamilton RL, Wecht CH. Chronic traumatic encephalopaty in a National Football League player. Neurosurgery. 2005;57(1):128-34.

19. Litsky F. Doug Kotar of Giants died; ex star of backfield was 32. The New York Times [Internet]. 17 de diciembre de 1983. [Consultado el 13 de julio de 2018]. 20. Pellman EJ, Viano DC, Tucker AM, Casson IR, Waeckerle JF. Concussion in professional football: reconstruction of game impacts and injuries. Neurosurgery. 2003;53(4):799-812.

21. Johncock B. John Paul Stapp: the fastest man on earths, who saved millions. The Spectator [Internet]. 14 de noviembre de 2015. [Consultado el 13 de julio de 2018].

22. McGurty F. Study finds evidence of brain injury in living NFL veterans. Sport News [Internet]. 11 de abril de 2016. [Consultado el 13 de julio de 2018].
23. Conidi FX. Sports Concussion Guidelines. Practical Neurology. July/August 2015. [Consultado el 13 de julio de 2018].

24. Conidi FX. What neurologist should know about Concussion, the Film. Neurology Advisor [Internet]. 29 de diciembre de 2015. [Consultado el 13 de julio de 2018].

25. Poole VN, Breedlove EL, Shenk TE, Abbas K, Robinson ME, Leverenz L, et al. Sub-concussive hit characteristics predict deviant brain metabolism in football athletes. Dev Neuropsychol. 2015 Jan;40(1):12-7.

26. Andrikopoulos J. Creating a Concussion Crisis and Chronic Traumatic Encephalopaty. JAMA Neurol. 2014;71(5):654.

27. Lepage C, Muelhmann M, Tripodis Y, Hufschmidt J, Stamm J, Green K et al. Limbic system structure columes and associated neurocognitive functioning in former NFL players. Brain Imaging Behav. 2018. doi: 10.1007/s11682-018-9895-z 28. Alosco ML, Tripodis $Y$, Fritts NG y cols. Cerebrospinal fluid tau, $A \beta$, and STREM2 in Former National Football League Players: Modeling the relationship between repetitive head impacts, microglial activation, and neurodegeneration. Alzheimer's and Dementia (2018). [Consultado el 13/07/2018].

29. Lagerstedt L, Egea-Guerrero JJ, Bustamante A, Rodríguez-Rodríguez A, El Rahal A, Quintana-Diaz M, et al. Combining H-FABP and GFAP increases the cacacity to differentiate between CT-postive and CT-negative patients with mild traumatic brain injury. PLoS One. 2018;13(7):e0200394.

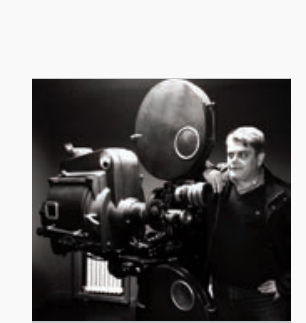

Licenciado en Medicina por la Universidad de Santiago de Compostela. Doctor en Medicina por la Universidad de Santiago de Compostela). Diplomado en Salud Pública. Máster en Gestión Sanitaria por la Universidad de Vigo. Máster en Derecho Sanitario por la Universidad de Castilla - La Mancha. Médico de Familia en el Centro de Saúde "Novoa Santos", Servizo Galego e Saúde, Ourense. Colaborador habitual de "La Región" (Ourense) y "Atlántico Diario" (Vigo). Autor de los blogs "Cartas de Aloysius" y "MEDYCINE". 